\title{
Heart rate in patients with reduced ejection fraction: relationship between single time point measurement and mean heart rate on prolonged implantable cardioverter defibrillator monitoring
}

\author{
Marlena V. Habal ${ }^{1}$, Kumaraswamy Nanthakumar ${ }^{1,2}$, Peter C. Austin ${ }^{1,3}$, Cassandra Freitas ${ }^{2,4}$, Christopher Labos ${ }^{3}$ \\ and Douglas S. Lee $1,2,3,4,5^{*}$ (D)
}

\begin{abstract}
Background: Heart rate (HR) is a prognostic marker that is increasingly used as a therapeutic target in patients with cardiovascular disease. The association between resting and mean HR remains unclear. We therefore set out to determine the relationship between resting HR on the electrocardiogram (ECG) obtained at a single time point, and mean HR on implantable cardioverter defibrillator (ICD) interrogation amongst patients with a reduced left ventricular ejection fraction (LVEF).

Methods: Prospective ICD data were obtained from 54 patients with LVEF < 40\%. Mean HR determined using the ICD HR histograms was compared with resting HR measured on the ECG performed in the clinic.

Results: Average resting and ICD mean HRs were $67.9 \pm 10.1$ and $67.8 \pm 9.6 \mathrm{bpm}$ respectively. There was good correlation in the overall cohort $(r=0.79)$, in those with resting ECG HRs $\leq 70 \mathrm{bpm}(r=0.62)$, and amongst the 27 patients on intermediate-to-high dose beta-blockers $(r=0.91)$. However, Bland-Altman analysis demonstrated wide limits of agreement in the overall cohort $(-12.5,12.7 \mathrm{bpm})$, at resting HRs $\leq 70 \mathrm{bpm}(-12.7,9.8 \mathrm{bpm})$, and on intermediate-to-high dose beta-blockers (-8.9, $7.4 \mathrm{bpm})$. Moreover, resting HR did not predict the 10-bpm interval where the most time was spent.
\end{abstract}

Conclusions: While resting HR correlated with mean HR in patients with reduced LVEF, and in important subgroups, the limits of agreement were unacceptably wide raising concern over the use of single time point resting $\mathrm{HR}$ as a therapeutic target.

Keywords: Mean heart rate, Resting heart rate, Beta-blockers

\section{Background}

Elevated heart rate (HR) has been associated with higher mortality in otherwise healthy individuals [1-3] and in those with coronary artery disease $[4,5]$. In the Framingham cohort, higher HR was associated with an increased risk of cardiovascular disease, heart failure, and death [6]. Our group and others have previously

\footnotetext{
* Correspondence: dlee@ices.on.ca

${ }^{1}$ University of Toronto, Toronto, ON, Canada

${ }^{2}$ Peter Munk Cardiac Centre, University Health Network, Toronto, ON, Canada Full list of author information is available at the end of the article
}

shown that an elevated HR is associated with increased all-cause and cardiovascular mortality as well as with 30-day re-hospitalization in chronic heart failure [7-9]. The negative effect of elevated HR on the myocardial supply-demand balance is implicated in this process and clinically, elevated HR has been associated with progression of atherosclerosis in patients with an MI at a young age [10] and plaque disruption [11].

Ivabradine, an $\mathrm{I}_{\mathrm{f}}$ current inhibitor that selectively lowers HR was initially shown to improve time to STsegment depression in patients with stable angina [12]. 
More recently, ivabradine was studied in the heart failure (HF) population where it reduced HF hospitalizations (SHIFT) [13] resulting in its inclusion as part of guideline recommended therapy for HF patients with $\mathrm{HR} \geq 70 \mathrm{bpm}$ despite optimal medical therapy [14, 15]. However, despite the growing interest in heart rate modulation as a target for therapeutic intervention, there is a paucity of literature on the optimal method of HR assessment.

While resting HR is commonly used in the clinical setting due to its simplicity, it has been shown that single time-point HR measurement reproducibility is poor with only modest correlation between resting HR and mean HR obtained on extended monitoring [16-18]. Moreover a recent study examining ambulatory monitoring suggested that continuous HR was an independent predictor of all-cause mortality after adjusting for resting HR while adjusted resting HR was not [19]. This has implications not only from a therapeutic perspective but also merits investigation to inform clinical trial design. Indeed, the ivabradine trials have shown mixed results both in the setting of ischemic heart disease [12, 20], and chronic HF [13, 21]. Therefore we sought to examine the relationship between resting and mean HR on prolonged monitoring in patients with reduced LVEF. However, because correlation does not necessarily imply agreement, we further sought to investigate the level of agreement between these measures in order to ascertain the safety and validity of these methods of HR determination.

\section{Methods}

\section{Study population and study design}

We prospectively recruited a convenience sample of patients with systolic dysfunction between April 2015 and March 2016 who were followed in the device clinic at Toronto General Hospital, a large tertiary care centre in the University Health Network, Toronto, Canada. Patients were eligible for inclusion if they were older than 18 years old, had an LVEF less than 40\%, had an ICD in situ, and were paced in the atrium or ventricle less than $20 \%$ of the time. Patients with an LVEF greater than or equal to $40 \%$, who were paced more than $20 \%$ of the time, who had a HR less than $40 \mathrm{bpm}$, or a paced rhythm on resting rhythm strip during their clinic visit were excluded. Patients with a left ventricular assist device or complex congenital heart disease were also excluded.

Baseline characteristics and device indication were obtained from the electronic patient record (EPR). Medication lists were obtained directly from the patient, or if not available, from the chart or EPR. Analyses were limited to those patients whose medication lists were documented within 13 weeks of HR assessment. Beta-adrenoreceptor blockers were stratified into low and intermediate-high dose categories. Carvedilol $\geq 12.5 \mathrm{mg}$ twice daily, bisoprolol $\geq 5 \mathrm{mg}$ daily, and metoprolol $\geq 50 \mathrm{mg}$ twice daily were considered to be intermediate-high doses. The intermediate-high dose category which we analyzed together, is consistent with high dose group in the recent OBTAIN study [22].

\section{Ascertainment of heart rate}

Resting HR was defined as that obtained from the device interrogation at the end of the clinic visit in the seated or recumbent position after the patient had been resting both prior to and during the clinic visit. Mean HR was obtained from the HR histogram available upon device interrogation. The HR histogram is divided into $10 \mathrm{bpm}$ heart rate intervals, (for example 60-69 bpm, 70$79 \mathrm{bpm}$, etc.) and provides the relative amount of time spent in each heart rate interval as a percentage of the total time since last device interrogation. Mean HR was calculated by taking the median of each 10-bpm heart rate interval and multiplying it by the percentage of time spent in that interval. The mean HR was the sum of the products calculated in each interval. The highest \% HR interval was defined as the 10 -bpm interval that the patient spent the most time in. If multiple $10-\mathrm{bpm}$ intervals had equal frequencies, the one closest to the resting HR was used. An illustrative example of our calculation of mean heart rate can be seen in Additional file 1: Figure S1.

\section{Outcomes}

The primary goal was to determine the agreement between resting HR on the ECG at a single time point and mean HR from the ICD interrogation. Secondary analyses included the correlation between resting $\mathrm{HR}$ and the highest \% HR interval. We also conducted a sensitivity analysis to examine the relationship in important subgroups including $\mathrm{HR} \leq 70 \mathrm{bpm}$, diabetics, patients with arrhythmias on interrogation (atrial fibrillation and ventricular tachycardia), those taking intermediate-high doses of beta-blockers, the subgroups with and without pacing on interrogation, and those with cardiac resychronization therapy (CRT).

\section{Statistical analysis}

Continuous variables are reported as mean \pm standard deviation and categorical variables as numbers (percentages). The correlation coefficient ( $r$ ) was determined for the association between resting $\mathrm{HR}$ and mean HR, as well as the association between resting HR and the highest \% HR interval. Percent agreement between the two HR measurements was assessed using Bland-Altman plots with $95 \%$ limits of agreement. Statistical analysis was performed using STATA version 12, StataCorp, College Station, Texas. 


\section{Results}

\section{Patient characteristics}

A total of 54 patients were included in the present study of which $41(76 \%)$ were male. The average age was $63.6 \pm 12.6$ years. The baseline characteristics are shown in Table 1. Twenty-four patients (44\%) had an LVEF between 20 and 29\% and 32 (59\%) had an ischemic etiology for their cardiomyopathy. With regards to the

Table 1 Baseline Characteristics

\begin{tabular}{|c|c|}
\hline Age (years) & $63.6 \pm 12.6$ \\
\hline Male, n (\%) & $41(76)$ \\
\hline \multicolumn{2}{|l|}{ Indication for ICD, n (\%) } \\
\hline $1^{\circ}$ & $41(76)$ \\
\hline $2^{\circ}$ & $13(24)$ \\
\hline Ischemic HF, n (\%) & $32(59)$ \\
\hline \multicolumn{2}{|l|}{ LVEF, n (\%) } \\
\hline $30-39$ & $16(30)$ \\
\hline $20-29$ & $24(44)$ \\
\hline$<20 \%$ & $14(26)$ \\
\hline \multicolumn{2}{|l|}{ Comorbidities, n (\%) } \\
\hline Hypertension & $29(54)$ \\
\hline Dyslipidemia & $30(56)$ \\
\hline Diabetes & $20(37)$ \\
\hline \multicolumn{2}{|l|}{ Device, n (\%) } \\
\hline Medtronic & $15(28)$ \\
\hline St. Jude & $34(63)$ \\
\hline Boston & $4(7)$ \\
\hline Biotronik & $1(2)$ \\
\hline Dual chamber, n (\%) & $36(67)$ \\
\hline CRT, n (\%) & $22(41)$ \\
\hline Paced $>1 \%, \mathrm{n}(\%)$ & $19(35)$ \\
\hline Mean time paced & $6.6 \%$ \\
\hline Atrial fibrillation history, n (\%) & $16(30)$ \\
\hline Atrial fibrillation on interrogation, $\mathrm{n}(\%)$ & $15(28)$ \\
\hline History of VTNF, n (\%) & $30(56)$ \\
\hline VT on interrogation, $\mathrm{n}(\%)$ & $6(11)$ \\
\hline NSVT on interrogation, n (\%) & $13(24)$ \\
\hline \multicolumn{2}{|l|}{ Medications, n(\%) } \\
\hline Beta-blockers & $39(100 \%)$ \\
\hline Amiodarone & $7(18 \%)$ \\
\hline Digoxin & $12(31 \%)$ \\
\hline ACEI or ARB & $37(95 \%)$ \\
\hline Mineralocorticoid antagonist & $29(74 \%)$ \\
\hline Furosemide & $24(62 \%)$ \\
\hline
\end{tabular}

ICD Implantable Cardioverter Defibrillator, HF heart failure, LVEF left ventricular systolic function, $C R T$ cardiac resynchronization therapy, $V T$ ventricular tachycardia, VF ventricular fibrillation, NSVT nonsustained ventricular tachycardia ${ }^{a}$ medication data were known and available for 39 patients
ICD indication, 41 devices (76\%) were for primary prevention. Nineteen patients $(35 \%)$ were paced $>1 \%$ in the chamber used to quantify heart rate (ie. excluding CRT) with an overall mean percentage time paced of $6.6 \%$.

\section{Association between resting and mean heart rate}

For the total study population, the mean resting HR was $67.9 \pm 10.1 \mathrm{bpm}$ and the ICD derived mean HR was $67.8 \pm 9.6 \mathrm{bpm}$. There was good linear correlation $(r=0.79 ; p<.001)$ between these two measurements (Fig. 1a). Using Bland-Altman analysis, the mean difference was minimal (0.1). However the limits of agreement were wide $(-12.5,12.7 \mathrm{bpm})$ (Fig. 1b). When the limits of agreement were set to $\pm 5 \mathrm{bpm}, 20$ (37\%) of the values fell outside of this range (Additional file 2: Figure S2).

\section{Association between resting heart rate $\leq 70 \mathrm{bpm}$ and mean heart rate}

The association between resting and mean $\mathrm{HR}$ in the subgroup with resting $\mathrm{HR} \leq 70-\mathrm{bpm}$ is presented in Fig. 2a. Moderate correlation $(r=0.62 ; p<.001)$ was found in this subgroup of patients. Bland-Altman analysis demonstrated a slight difference between resting and mean HR (-1.4 bpm) (Fig. 2b). Similar to the overall cohort, the limits of agreement were wide $(-12.7,9.8 \mathrm{bpm})$. When the limits of agreement were set to $\pm 5 \mathrm{bpm}, 11$ (30.6\%) of the values fell outside of this range.

\section{Association between resting heart rate and mean heart rate in patients prescribed beta-blockers}

We performed a sensitivity analysis for the 39 patients for whom beta-blocker dose was recorded. There was excellent correlation $(r=0.91, p<.001)$ between the resting and mean HR amongst patients taking intermediate-tohigh dose beta-blockers (Fig. 3a). Bland-Altman analysis demonstrated minimal mean difference $(-0.74 \mathrm{bpm})$ with narrower limits of agreement than for the overall cohort (-8.9, 7.4 bpm) (Fig. 3b). When the limits of agreement were set to $\pm 5 \mathrm{bpm}, 7$ (25.9\%) of the values fell outside of this range.

\section{Association between resting heart rate and mean heart rate in subgroup analysis}

Since HR and HR variability are influenced by diabetic neuropathy, we performed a sensitivity analysis for the 20 patients with documented diabetes. Amongst this subgroup, the average ECG HR and ICD HR was $69.5 \pm 7.6$ and $70.2 \pm 8.7$, respectively. Correlation between resting and ICD HR was moderate $(r=0.61$, limits of agreement - 15.0, 13.5). We also performed sensitivity analysis for the 16 patients with ventricular tachycardia or nonsustained ventricular tachycardia on interrogation. Correlation was strong with persistently wide limits of 

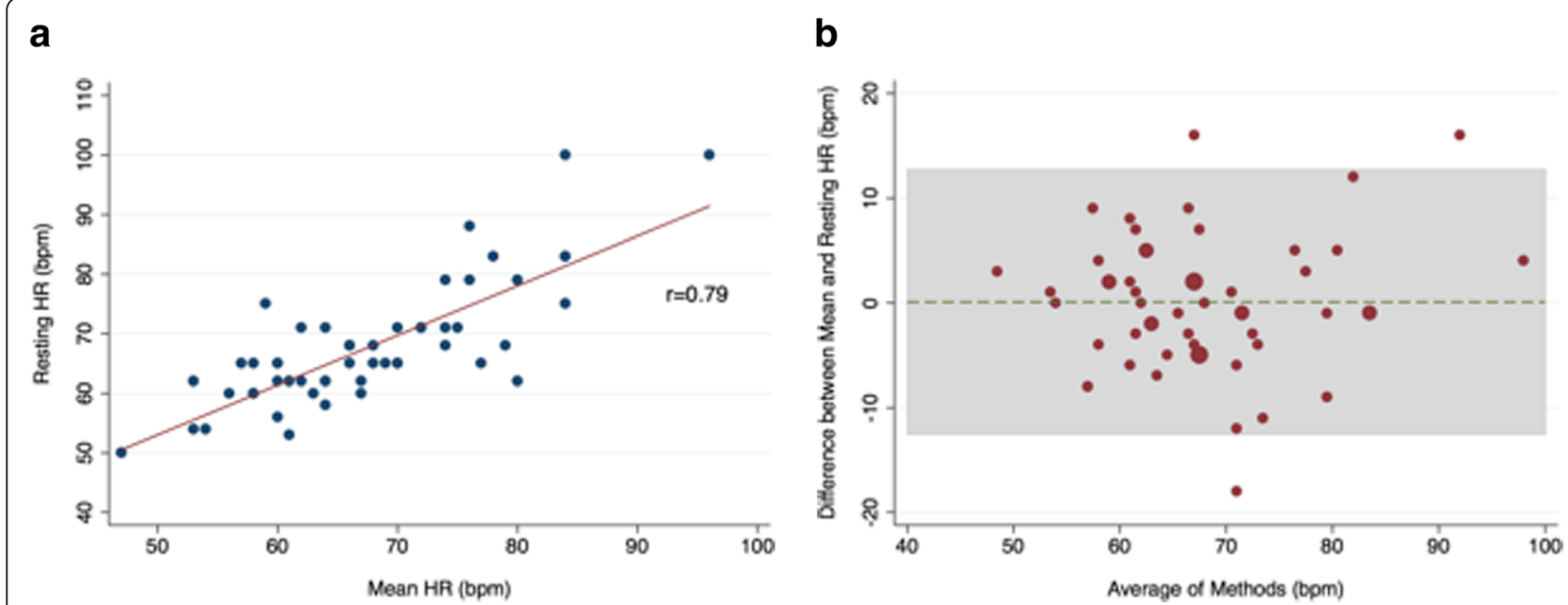

Fig. 1 a Resting HR/mean HR. b Bland-Altman Plot of resting HR/mean HR. HR, heart rate

agreement $(r=0.93$, limits of agreement $-8.0,8.8 \mathrm{bpm})$. Given that pacing could affect the ICD HR, we performed a sensitivity analysis of the patients paced $<1 \%$ in the cardiac chamber from which the mean HR was determined, those paced $>1 \%$, and those with a CRT device in situ (Additional file 3: Table S1). In all three groups the mean difference remained low $(0.3,-0.2$, and -0.7 respectively), the correlation was moderate to strong $(0.80,0.60$, and 0.61 respectively), and the limits of agreement were wide $(-13.6,14.1 ;-9.8,9.4 ;-14.2$, 12.7 respectively).

\section{Association between resting heart rate and heart rate interval}

To further validate our findings, we sought to determine whether resting $H R$ could predict the HR interval in which a patient spent the most time. Data were categorized by 10-bpm intervals on the histogram and compared with the resting HR. In the overall cohort, $28 \%(n=15)$ had a resting HR above the highest \% HR interval, 50\% $(n=27)$ had a resting HR within this interval, and $22 \%(n=12)$ had a resting HR below the highest $\%$ interval (Table 2). In the subgroup with $\mathrm{HR} \leq 70 \mathrm{bpm}$ $(n=36), 22 \%(n=8)$ had a resting HR above the highest $\%$ HR interval, $47 \%(n=17)$ had a HR within this interval, and $31 \%(n=11)$ had a resting HR below the highest $\%$ HR interval (Table 2).

\section{Discussion}

In the present, hypothesis generating study, we examined a novel method of mean HR determination from prolonged ICD monitoring. Although our data demonstrated good correlation between resting and mean HR with minimal systematic bias between the 2 methods,
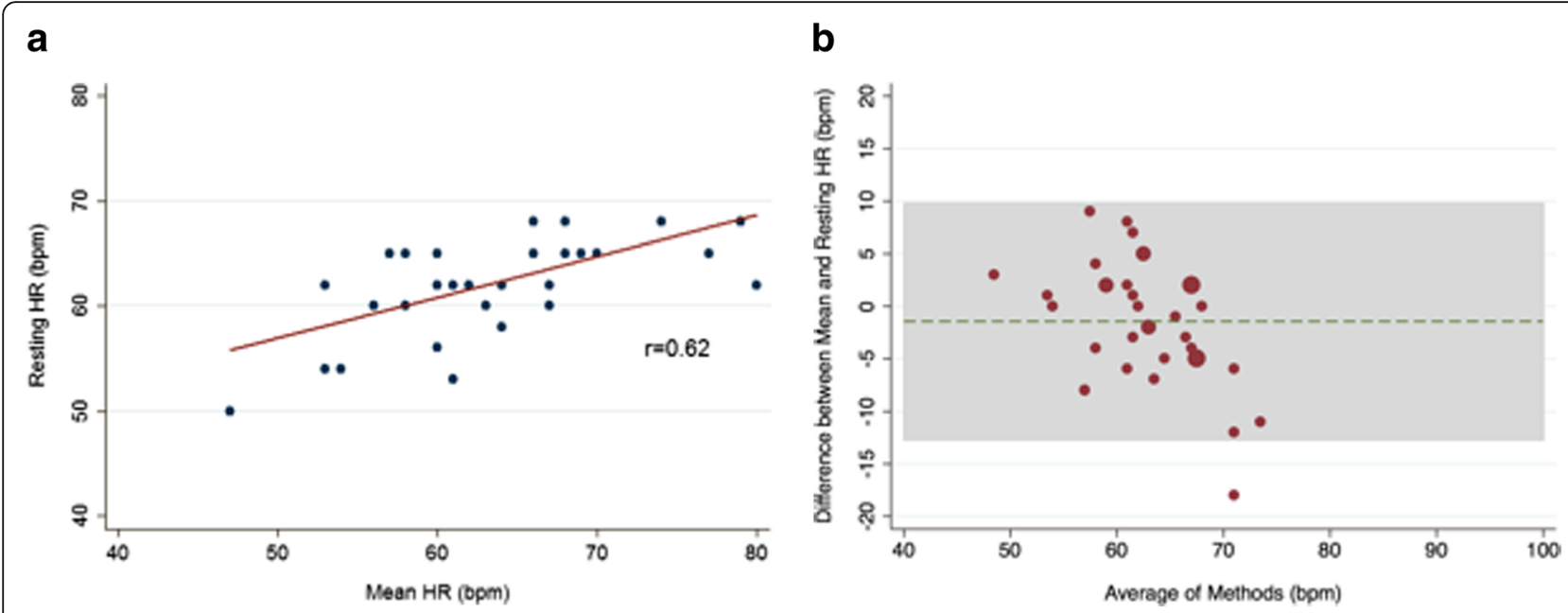

Fig. 2 a Resting $H R /$ mean $H R$ amongst the subgroup with resting $H R \leq 70 \mathrm{bpm}$. b Bland-Altman Plot of resting HR/mean HR amongst the subgroup with resting $H R \leq 70 \mathrm{bpm}$ 

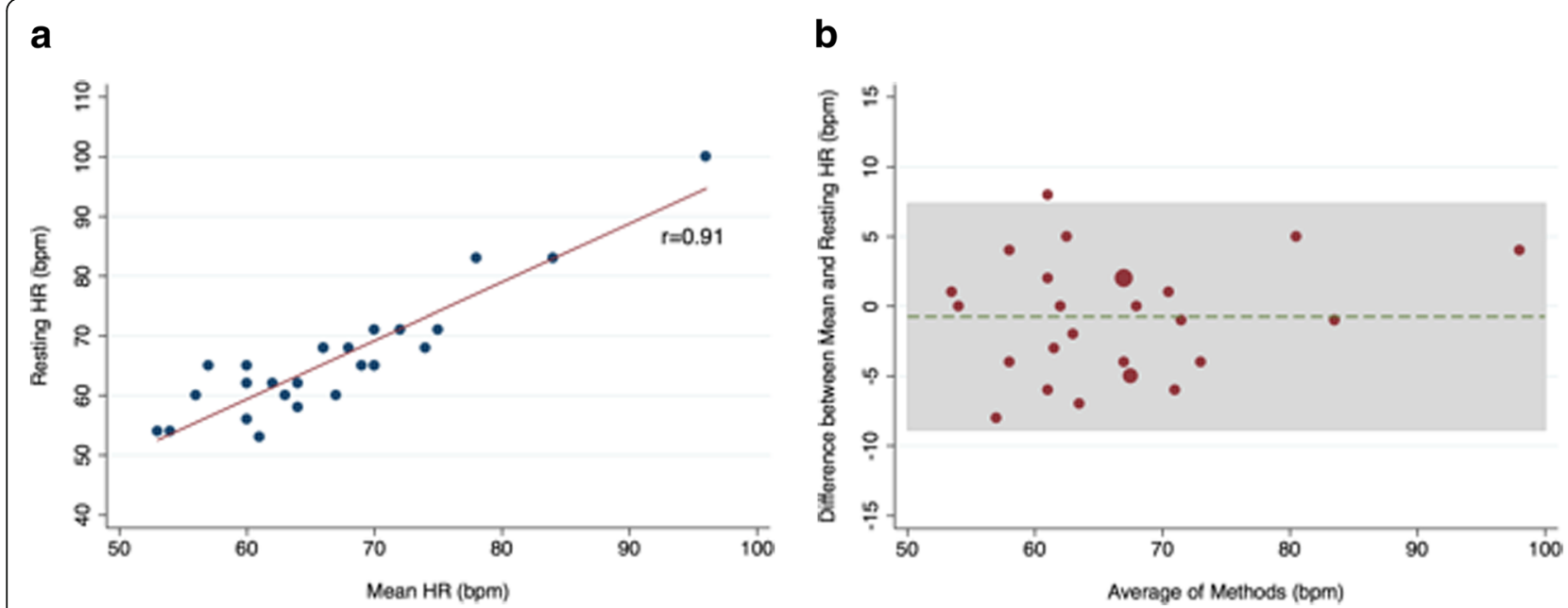

Fig. 3 a Resting HR/mean HR in the subgroup on an intermediate-to-high dose beta-blocker. b Bland-Altman Plot of resting HR/mean HR in the subgroup on an intermediate-to-high dose beta-blocker

the limits of agreement were unacceptably wide. Since there is no gold standard for HR determination we further assessed whether resting HR obtained at a single time point could predict the highest frequency HR interval over the duration of ICD monitoring. Our findings demonstrated that resting HR only reflected the highest frequency $H R$ interval half of the time as determined from the HR histogram. Importantly, resting HR more frequently overestimated the HR interval than underestimated it. From a clinical perspective, this suggests that single time point resting $\mathrm{HR}$ is an imperfect surrogate for mean HR when titrating pharmacotherapies.

Our findings of correlation between methods are consistent with other small studies comparing resting and HRs obtained by Holter monitoring. Carlson et al., found partial correlation between resting ECG HR and both mean daytime HR as well as resting HR determined by Holter monitoring in a cohort of otherwise healthy participants [17]. The strength of correlation was weaker than in the present study, which may be explained by the lower activity levels of the patients in our study as well as lower heart rate variability. Moreover, the routine

Table 2 Agreement between resting HR and 10-bpm HR interval

\begin{tabular}{|c|c|c|c|c|}
\hline & \multicolumn{2}{|c|}{$\begin{array}{l}\text { Overall cohort } \\
(n=54)\end{array}$} & \multicolumn{2}{|c|}{$\begin{array}{l}\text { Resting } H R \leq 70 \mathrm{bpm} \\
(n=36)\end{array}$} \\
\hline & $N$ & $\%$ & $N$ & $\%$ \\
\hline $\begin{array}{l}\text { Resting HR higher than } \\
\text { highest\% HR interval }\end{array}$ & 15 & $28 \%$ & 8 & $22 \%$ \\
\hline $\begin{array}{l}\text { Resting HR within } \\
\text { highest\% HR interval }\end{array}$ & 27 & $50 \%$ & 17 & $47 \%$ \\
\hline $\begin{array}{l}\text { Resting HR below highest\% } \\
\text { HR interval }\end{array}$ & 12 & $22 \%$ & 11 & $31 \%$ \\
\hline
\end{tabular}

$H R$ heart rate use of beta-blockers in this population would be expected to further contribute as evidenced by the strong correlation between methods in the subgroup on an intermediate-to-high dose beta-blocker. Furthermore, in a telemonitoring study of ICD patients with NYHA class III heart failure, resting HR correlated with mean 24-h HR [18]. More recently Jolly et al., showed a positive correlation between ambulatory Holter mean HR and ECG resting HR in patients with atrial fibrillation [23].

Our study extends the literature by demonstrating that correlation between methods for determining HR does not necessarily imply that the two different approaches yield the same measurements. After confirming correlation, we determined that the limits of agreement between resting single time point $H R$ and mean $H R$ on prolonged monitoring were wide. While there is no consensus on how wide a limit of agreement is acceptable, from a clinical perspective, a 10-bpm difference would be likely to alter clinical decision-making. When the limits of agreement were set to a clinically meaningful interval of $\pm 5 \mathrm{bpm}, 37 \%$ of patients fell outside of this range. Furthermore, we demonstrated that resting HR was frequently above the mean $\mathrm{HR}$, which is consistent with the findings of Pastor-Perez et al., who identified a subgroup of patients with HF in whom resting HR was above the mean with 7-day ambulatory HR monitoring [24].

The present findings, both using Bland-Altman analysis and comparing resting HR to the highest frequency heart rate interval, raise concern for iatrogenic bradycardia when resting ECG heart rate is used to titrate therapies. This issue was clinically highlighted in both the SHIFT [13] (Systolic Heart failure treatment with the $I_{f}$ inhibitor ivabradine Trial) and SIGNIFY [20] (Study Assessing the Morbidity-Mortality Benefits of the 
I Inhibitor Ivabradine in Patients with Coronary Artery Disease) trials where resting ECG was used to measure heart rate. In these trials, the rate of bradycardia in the treatment arm was $10.3 \%$ and $18.9 \%$ respectively. Thus, uptitrating HR lowering therapies, such as ivabradine, using a resting ECG has the potential for detrimental outcomes particularly given that it has never demonstrated an independent mortality benefit in this population. Clinically this iatrogenic bradycardia may result in failure to augment cardiac output sufficiently to maintain adequate perfusion with ensuing presyncope and falls. Moreover, while there is no consensus on the lower HR limit for a mortality benefit, our group found a non-significant trend towards increased 30-day mortality in a cohort of community-based HF patients with $\mathrm{HR}<60 \mathrm{bpm}$ [7]. Furthermore, in the MESA cohort, there was a U-shaped mortality distribution amongst individuals taking HR-modifying therapies with increased mortality at $\mathrm{HR}<50 \mathrm{bpm}$ on resting ECG [25]. Finally, in a heart failure population such as ours, who frequently are recipients of an ICD or pacemaker, over titration of medications may result in increased RV pacing which also carries negative prognostic implications [26]. In the context of these concerns, our findings suggest that an alternative method of HR assessment to supplement single time point measurements, should be considered by clinicians. Since many of these patients will have an ICD, either the mean HR or highest frequency HR interval could be used in order to reduce the risk of iatrogenic bradycardia. Long-term studies are then required to assess whether this method will also have prognostic implications.

Our study has several limitations. Firstly, mean HR could not be directly assessed from the ICD, as most commercially available devices do not offer this function. However, we developed a novel method of mean HR determination using the HR histogram which demonstrated strong correlation with resting HR, confirming its validity as a tool to measure HR. Secondly, the presence of tachyarrhythmias such atrial fibrillation or ventricular tachycardia could have influenced the results. With respect to atrial fibrillation, the documented burden was low and only three of these patients had single lead device in which case it would have been difficult to assess the atrial fibrillation burden. The episodes of NSVT/VT were also brief and unlikely to have affected the overall results. Our sensitivity analyses of these subgroups demonstrated results similar to the overall cohort, with moderate to good correlation but wide limits of agreement.

Thirdly, resting HR was taken at a single time point near the end of the clinic visit after the patient had been seated or recumbent and thus, in some instances the patient may have moved or become anxious, thus transiently raising their resting HR. However, this would have been expected to weaken the correlation between the two methods of measurement, which nonetheless remained robust. Fourthly, it is possible that the betablocker dose was adjusted during the time between device interrogations. However, it is equally likely that the doses would be increased or decreased. Given that this would result in non-differential misclassification, it would bias the results toward the null and thus is unlikely to affect the finding of the present study.

\section{Conclusion}

In conclusion, while there is good correlation between single time point resting $H R$ and mean $H R$ as determined from the ICD histogram, the limits of agreement are unacceptably wide and resting $\mathrm{HR}$ is frequently above the mean. These findings raise concern for the current clinical strategy of using a single time point method of heart rate assessment to titrate negative chronotropic therapies, which may result in iatrogenic bradycardia. Further studies are warranted to address the prognostic implications of these findings and the relative safety of these two methods when titrating chronotropic therapies.

\section{Additional files}

Additional file 1: Figure S1. Mean HR determination from the device histogram. HR, heart rate. (TIFF $159 \mathrm{~kb}$ )

Additional file 2: Figure S2. Bland-Altman analysis for the overall cohort with limits of agreement set to \pm 5 bpm from the bias. (TIFF $294 \mathrm{~kb}$ )

Additional file 3: Table S1. Correlation and agreement between single time point and ICD heart rate in the unpaced, paced, and CRT paced subgroups. (DOCX $14 \mathrm{~kb}$ )

\section{Abbreviations}

ECG: Electrocardiogram; HR: Heart rate; ICD: Implantable cardioverter defibrillator; LVEF: Left ventricular ejection fraction

\section{Acknowledgements}

Not applicable.

\section{Funding}

The Institute for Clinical Evaluative Sciences (ICES) is supported in part by a grant from the Ontario Ministry of Health and Long-Term Care. The opinions, results and conclusions are those of the authors and no endorsement by the Ministry of Health and Long-Term Care or by the Institute for Clinical Evaluative Sciences is intended or should be inferred.

This study was supported by a Foundation Grant from the Canadian Institutes of Health Research (grant \# FDN 148446). Dr. Lee is supported by a mid-career investigator award from the Heart and Stroke Foundation and the Ted Rogers Chair in Heart Function Outcomes, a joint Hospital-University Chair of the University Health Network and the University of Toronto. Dr. Austin is supported by a Career Investigator Award from the Heart and Stroke Foundation of Ontario.

Availability of data and materials

The datasets generated and/or analysed during the current study are not publicly available due to patient privacy but are available from the corresponding author on reasonable request. 


\section{Authors' contributions}

MVH and DSL conceived the idea for the study. MVH, DSL and KN designed the study. MVH drafted the manuscript. MVH, PCA and CL analyzed the data. DSL and KN provided supervision. DSL,CF and CL critically revised the manuscript. $\mathrm{KN}, \mathrm{CL}$ and CF prepared the manuscript for submission. DSL provided the funding for the study. All authors read and approved the final manuscript.

\section{Ethics approval and consent to participate}

The study was approved by the University Health Network Research Ethics Board and is in accordance with the guidelines outlined in the 1975 Declaration of Helsinki. After obtaining written informed consent from each patient, a rhythm strip and the HR histogram were printed following the patient's regularly scheduled device interrogation.

\section{Consent for publication}

Not applicable.

\section{Competing interests}

The authors declare that they have no competing interests.

\section{Publisher's Note}

Springer Nature remains neutral with regard to jurisdictional claims in published maps and institutional affiliations.

\section{Author details}

'University of Toronto, Toronto, ON, Canada. ${ }^{2}$ Peter Munk Cardiac Centre, University Health Network, Toronto, ON, Canada. ${ }^{3}$ Institute for Clinical Evaluative Sciences, Toronto, ON, Canada. ${ }^{4}$ Ted Rogers Centre for Heart Research, Toronto, ON, Canada. ${ }^{5}$ University Health Network, Toronto General Hospital, 200 Elizabeth Street, 4NU-482, Toronto, ON M5G 2C4, Canada.

\section{Received: 19 September 2017 Accepted: 18 January 2018}

\section{Published online: 31 January 2018}

\section{References}

1. Jensen MT, Marott $J$, Allin KH, Nordestgaard BG, Jensen GB. Resting heart rate is associated with cardiovascular and all-cause mortality after adjusting for inflammatory markers: the Copenhagen City heart study. Eur J Prev Cardiol. 2012;19(1):102-8.

2. Dyer AR, Persky V, Stamler J, Paul O, Shekelle RB, Berkson DM, et al. Heart rate as a prognostic factor for coronary heart disease and mortality: findings in three Chicago epidemiologic studies. Am J Epidemiol. 1980;112:736-49.

3. Jouven X, Empana JP, Schwartz PJ, Desnos M, Courbon D, Ducimetiere P. Heart-rate profile during exercise as a predictor of sudden death. N Engl J Med. 2005;352:1951-8.

4. Hjalmarson A, Gilpin EA, Kjekshus J, Schieman G, Nicod P, et al. Influence of heart rate on mortality after acute myocardial infarction. Am J Cardiol. 1990:65:547-53.

5. Diaz A, Bourassa MG, Guertin MC, Tardif JC. Long-term prognostic value of resting heart rate in patients with suspected or proven coronary artery disease. Eur Heart J. 2005;26:967-74.

6. Ho JE, Bittner V, Demicco DA, Breazna A, Deedwania PC, Waters DD. Usefulness of heart rate at rest as a predictor of mortality, hospitalization for heart failure, myocardial infarction, and stroke in patients with stable coronary heart disease. Am J Cardiol. 2010;105:905-11.

7. Habal MV, Liu PP, Austin PC, Ross HJ, Newton GE, Wang X, et al. Association of Heart Rate at hospital discharge with mortality and hospitalizations in patients with heart failure. Circ Heart Fail. 2014;7:12-20.

8. Laskey WK, Alomari I, Cox M, Schulte P, Zhao X, Hernandez AF, et al. Heart rate at hospital discharge in patients with heart failure is associated with mortality and Rehospitalization. J Am Heart Assoc. 2015;4:e001626. https://doi.org/10.1161/JAHA.114.001626.

9. Castagno D, Skali H, Takeuchi M, Swedberg K, Yusuf S, Michelson EL, et al. Association of Heart Rate and Outcomes in a broad Spectrum of patients with chronic heart failure. J Am Coll Cardiol. 2012;59:1785-95.

10. Perski A, Olsson G, Landou C, de Faire U, Theorell T, et al. Minimum heart rate and coronary atherosclerosis: independent relations to global severity and rate of progression of angiographic lesions in men with myocardial infarction at a young age. Am Heart J. 1992;123:609-16.

11. Heidland UE, Stauer BE. Left ventricular muscle mass and elevated heart rate are associated with coronary plaque disruption. Circulation. 2001;104:1477-82.
12. Borer JS, Fox K, Jaillon P, Lerebours G. Antianginal and antiischemic effects of ivabradine, an If inhibitor, in stable angina. A randomized, double-blind, multicentered, placebo-controlled trial. Circulation. 2003;107:817-23.

13. Swedberg K, Komajda M, Bohm M, Borer JS, Ford I, Dubost-Brama A, et al. SHIFT investigators. Heart rate as a risk factor in chronic heart failure (SHIFT): the association between heart rate and outcomes in a randomized placebo-controlled trial. Lancet. 2010;376:886-94.

14. Howlett J, Chan M, Ezekowitz J, Harkness K, Heckman G, Kouz S, et al. The Canadian cardiovascular society heart failure companion: bridging guidelines to your practice. Can J Cardiol. 2016;32:296-310.

15. Ponikowski P, Voors AA, Anker SD, Bueno H, Cleland JG, Coats AJ et al. 2016 ESC Guidelines for the diagnosis and treatment of acute and chronic heart failure: The Task Force for the diagnosis and treatment of acute and chronic heart failure of the European Society of Cardiology (ESC) Developed with the special contribution of the Heart Failure Association (HFA) of the ESC. Eur Heart J. 2016;37:2129-200

16. Palatini P, Winnicki M, Santonastaso M, De Venuto G, Zanata G, Bertolo O, et al. Reproducibility of heart rate measured in the clinic and with 24-hour intermittent recorders. Am J Hypertens. 2000;13:92-8.

17. Carlson N, Dixen U, Marott JL, Jensen MT, Jensen GB. Predictive value of casual ECG-based resting heart rate compared with resting heart rate obtained from Holter recording. Scand J Clin Lab Invest. 2014;74:163-9.

18. Lieback A, Proff J, Weeel K, Fleck E, Gotze S. Remote monitoring of heart failure patients using implantable cardiac pacing devices and external sensors: results of the insight-HF study. Clin Res Cardiol. 2012;101:101-7.

19. Korshoj M, Lidegaard M, Kittel F, Van Herck K, De Backer G et al. The Relation of Ambulatory Heart Rate with All-Cause Mortality among Middle-Aged Men: A prospective Cohort Study. PLoS One. 2015. https://doi.org/10.1371/journal.pone.0121729.

20. Fox K, Ford I, Steg PG, Tardif M, Ferrari R, et al. Ivabradine in stable coronary artery disease without clinical heart failure. NEJM. 2014;371:1091-9.

21. Fox K, Ford I, Steg PG, Tendera M, Ferrari R, et al. Ivabradine for patients with stable coronary artery disease and left-ventricular systolic dysfunction (BEAUTIFUL): a randomized, double-blind, placebo-controlled trial. Lancet. 2008:372:807-16.

22. Goldberger JJ, Bonow RO, Cuffe M, Liu L, Rosenberg $Y$, et al. Effect of Beta-blocker dose on survival after acute myocardial infarction. J Am Coll Cardiol. 2015;66:1431-41.

23. Jolly US, Klein G. Utility of ambulatory Holter monitoring in patients with permanent Atrial fibrillation. Can J Cardiol. 2015;31:S246.

24. Pastor-Perez FJ, Manzano-Fernandez S, Goya-Esteban R, Pascual-Figal DA, Bravo IP, Barquero-Perez O, et al. Heart rate control in chronic heart failure: resting versus mean heart rate with prolonged ambulatory ECG recording. Int J Cardiol. 2013;170:e45-7.

25. Dharod A, Soliman EZ, Dawood F, Chen H, Shea S, et al. Association of Asymptomatic Bradycardia with Incident Cardiovascular Disease and Mortality: the multi-ethnic study of atherosclerosis. JAMA Intern Med. 2016:176:219-27.

26. Wilkoff B, Cook J, Epstein A, Greene HL, Hallstrom AP, Hsia H, et al. Dual chamber pacing or ventricular backup pacing in patients with an implantable defibrillator. The dual chamber and WI implantable defibrillator (DAVID) trial. JAMA. 2002;288(24):2123-3115.

\section{Submit your next manuscript to BioMed Central and we will help you at every step:}

- We accept pre-submission inquiries

- Our selector tool helps you to find the most relevant journal

- We provide round the clock customer support

- Convenient online submission

- Thorough peer review

- Inclusion in PubMed and all major indexing services

- Maximum visibility for your research

Submit your manuscript at www.biomedcentral.com/submit 